\title{
Clinical Practice Recurrent Severe Obscure Gastro Intestinal- Bleeding in a 20 Year Old Man \\ Breidert M, ${ }^{1}$ Mandal $A,{ }^{2}$ Koller $A,{ }^{3}$ Huellebrand N, ${ }^{3}$ Malla $B,{ }^{4}$
}

\author{
Department of Internal Medicine \\ ${ }^{1}$ District Hospital Clinic Altmühltal \\ Germany, Teaching Hospital of the Technical University \\ Munich, Germany \\ ${ }^{2}$ Dhulikhel Hospital- Kathmandu University Hospital \\ Teaching Hospital of the University of Kathmandu \\ Nepal \\ ${ }^{3}$ Department of Visceral Surgery \\ District Hospital Clinic Altmühltal,
}

Germany, Teaching Hospital of the Technical University Munich, Germany

${ }^{4}$ Department of Surgery

Dhulikhel Hospital- Kathmandu University Hospital Teaching Hospital of the University of Kathmandu Nepal

\section{Corresponding Author}

Matthias Breidert

District Hospital Clinic Altmühltal

Germany, Teaching Hospital of the Technical University Munich, Germany

E-mail: matthias.Breidert@Klinik-Koesching.de

Citation

Breidert M, Mandal A, Koller A, Huellebrand N, Malla B. Clinical Practice Recurrent Severe Obscure Gastro Intestinal - Bleeding in a 20 Year Old Man. Kathmandu Univ Med J 2013;41(1):81-85.

\begin{abstract}
Morbus Osler-Weber-Rendu syndrome also known as Hereditary hemorrhagic telangiectasia (HHT) and Meckel's diverticulum is a rare combination disorder. Our case presented with the recurrent obscure gastrointestinal (GI) bleeding for several years. He came with a massive active lower gastrointestinal bleeding. Ultimatively, he underwent an exploratory laparotomy along with intraoperative colonoscopy. A Meckel's diverticulum in combination with multiple erosions was found as a probable cause of the massive gastrointestinal bleeding. An ileo-caeacal resection had been performed and by the pathologist multiple telangiectasias in the resected ileum were established. Blood was sent for genetics and was negative for ENG, ALK-1, and SMAD-4 genes. The patient was discharged after 10 days from time of admission and is under regular follow up without any further bleeding. In this case, despite sophisticated techniques for investigations the cause of the Gl-bleeding with several esophagogastroduodenoscopies and colonoscopies, mesenteric angiography and finally an oral double balloon enteroscopy was misdiagnosed till the intra operative endoscopy showed a middle Gl-bleeding. The management for obscure Gl-bleeding is discussed for countries with lower medical facilities like Nepal in our case with Morbus Osler-Weber-Rendu syndrome.
\end{abstract}

\section{KEY WORDS}

Meckel's diverticulum, middle gastrointestinal bleeding, morbus osler-weber-rendu

\section{INTRODUCTION}

A Meckel's diverticulum is a vestigial remnant of the omphalomesenteric (vitellointestinal) duct. ${ }^{1}$ As a congenital anomaly, it is a true diverticulum that includes all three coats of the small intestine. Generally, a Meckel's diverticulum ranges from $1-12 \mathrm{~cm}$ in length and is found 45 $90 \mathrm{~cm}$ proximal to the ileocecal valve. ${ }^{1}$

Morbus Osler-Weber-Rendu syndrome, also known as hereditary hemorrhagic telangiectasia (HHT) is an uncommon, autosomal dominant disorder characterized by telangiectasias that develop in the skin, mucous membranes and visceral organs. Although recognized as a rare disease, recent studies suggest HHT may be more prevalent than previously thought. ${ }^{2}$

The combination of Meckel's diverticulum and Morbus Osler-Weber-Rendu as a cause of middle gastrointestinal bleeding is very rare. Here we present a case of recurrent obscure bleeding which was misdiagnosed for several years. 


\section{CASE REPORT}

A 20-year-old man presented to our hospital at 11 p.m. with the chief complaint of blood in his stool. The patient continued to have intermittent rectal bleeding over the last six years, twice requiring blood transfusions, and he had evaluations of both the small and large bowels at other hospitals, with several esophagogastroduodenoscopies and colonoscopies.

His medical history was without any other significant findings, no alcohol, and drug intake for pain killers or anabolic substances were reported. He had not travelled abroad recently. There was a family history of HHT to his father.

Physical examination on admission revealed a BMI of 20 $\mathrm{kg} / \mathrm{m}^{2}$; his blood pressure was $110 / 80 \mathrm{mmHg}$ with a pulse rate of $110 \mathrm{bpm}$. Investigation revealed anemia (microcytic hypochronic) with a $\mathrm{Hb}$ of $6.9 \mathrm{~g} / \mathrm{dl}$ and the results of full blood count, electrolytes, glucose, inflammatory markers, clotting and coagulation studies, cholesterol and lipase were all normal. Urine analysis did not show any abnormal findings.

Normal saline was administered intravenously. The hematocrit, measured twice daily, remained stable. Chest $\mathrm{x}$-ray was normal and ultrasound of abdomen was done to rule out arterio-venous malformation in the liver or any intraabominal pathology.

Colonoscopy performed next day at 1 a.m. after admission revealed telangiectasia in the terminal ileum with bleeding (Fig. 1). Eight hours later gastroduodenoscopy showed no bleeding. Even oral double balloon endoscopy at afternoon was normal (introduced up to $320 \mathrm{~cm}$ ). However, lower double balloon endoscopy was not successful due to unable to intubate ileocaecal valve. Thereafter, on the same day at 7 p.m.mesenteric arteriography was performed which did not show any bleeding source (Fig. 2). Two days later

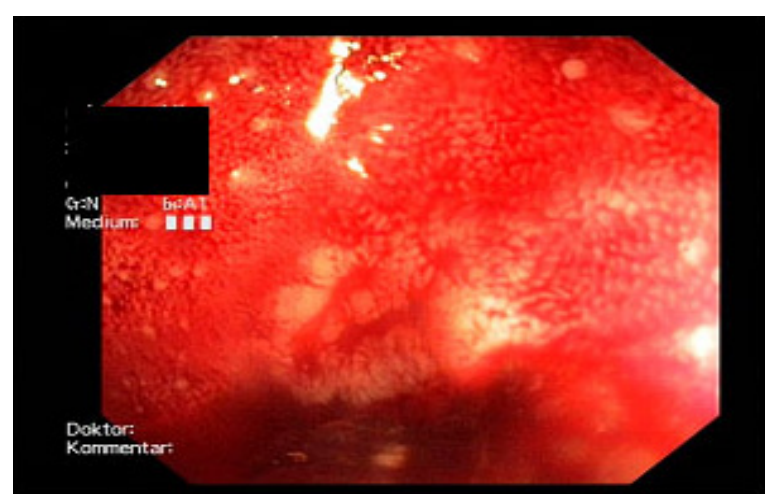

Figure 1. Colonoscopy at admission (21.9.: 1 a.m.): acute bleeding coming from the terminal ileum.

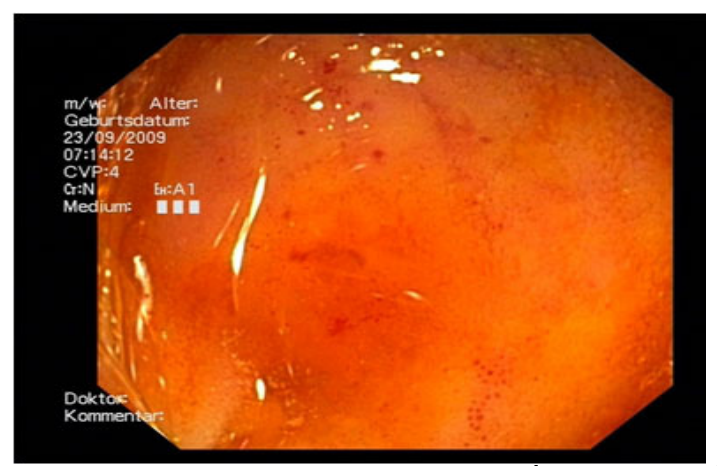

Figure. 3a, 3b. Repeated colonoscopy (23.9.: 10 a.m.): arrows show small telangiectasias.
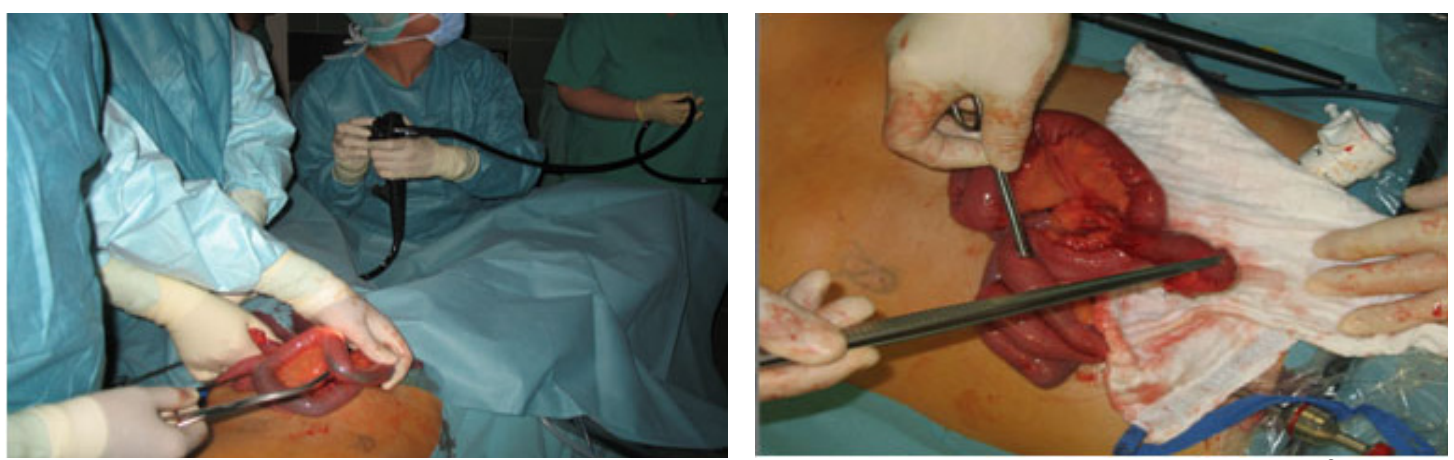

Figure 4a, 4b. Surgeons and gastroenterologist during intraoperative colonscopy via laparoscopic opening of terminal. Ileum (a). Meckel`s diverticulum incidentally identified during laparoscopic surgery (b). 

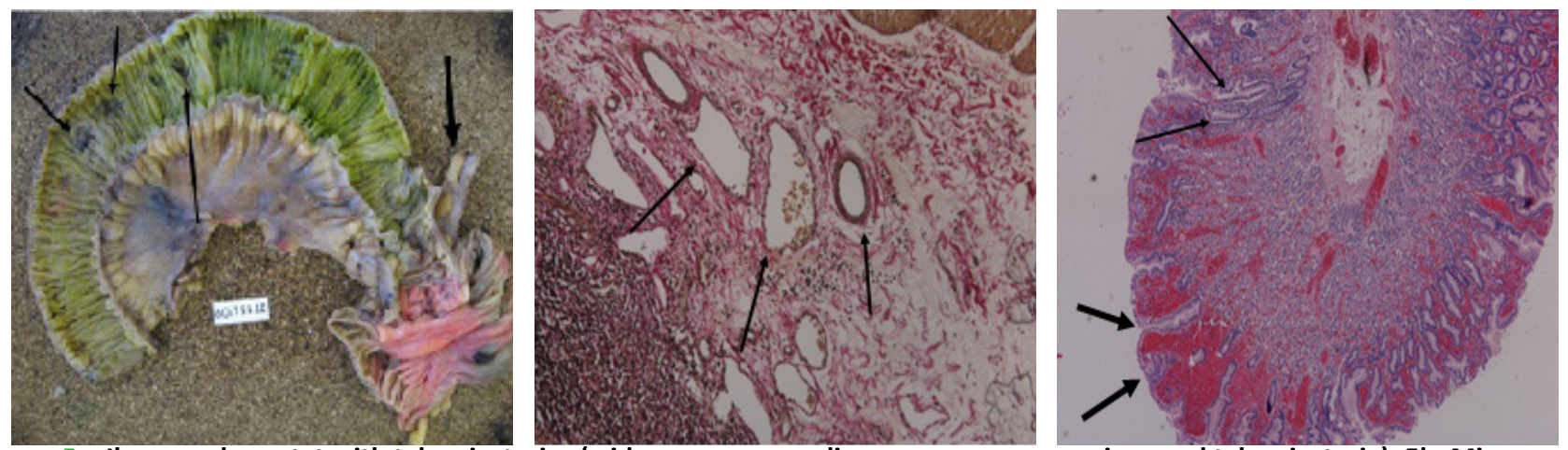

Figure 5a. lleocoecalresectat with telangiectasias (wide arrow: appendix; narrow arrow: erosions and telangiectasia). 5b: Microscopy (staining elastica von Gieson: $x$ 250): arrows show the arterio-venous malformations in the resected ileum. $5 \mathrm{c}$ : Overview from Meckel's diverticulum (staining with H\&E: $4 x$ ): narrow arrows show the ileum mucosa (goblets cells), wide arrow the heterotopic mucosa of stomach with bleedings.

colonoscopy was again done for rebleeding which showed now again bleeding at 10.a.m from the terminal ileum (Fig. $3 a, b)$. On the same day at 3 p.m laparoscopy was performed, a Meckel's diverticulum was found and - eventerated over a small incision - a intraoperative endoscopy was done (Fig. 4a) through the opened Meckels diverticulum, which surprisingly revealed bleeding Meckel's diverticulum with a lot of telangiectasias distal to the Meckel's diverticulum (Fig. 4 b).

During surgery, $20 \mathrm{~cm}$ of distal terminal ileum and the diverticulum (50 $\mathrm{cm}$ proximal the ileocaecal valve) has been resected and sent for histopathological examination which revealed multiple erosions in the ileum along with telangiectasias in the ileum and caecum. Meckel's diverticulum with a single erosion and telangiectasia were also reported (Fig. 5 a-c).

EDTA-blood was also sent for molecular genetics for ENG, ALK-1, SMAD-4 genes which did not show any mutation for HHT.

The patient improved symptomatically a week after surgery without any episodes of rebleeding and therefore discharged on day 10 with supportive management. The patient was followed up for a year without any history of rebleeding.

\section{DISCUSSION}

The most common causes of obscure bleeding in less than 40 years old patients are tumor, Meckel's diverticulum, Dieulafoy's lesion, and Crohn's disease.(Table 1) Our patient presented initially with a massive gastrointestinal bleeding due to Meckel's diverticulum in combination with HHT. The disorder of HHT is a rare cause of middle gastrointestinal bleeding in young patients. ${ }^{3}$ The presented case with the combination of Meckel's diverticulum and HHT as a most probable cause of obscure gastrointestinal bleeding is until yet not described in literature.

Meckel's diverticulum is most commonly discovered as an incidental finding on laparotomy or laparoscopy. Meckel's diverticulum can be associated with life-threatening
Table 1. Causes of middle and lower gastrointestinal bleeding ${ }^{3}$

\begin{tabular}{ll}
\hline $\begin{array}{l}\text { Upper gastrointestinal bleeding } \\
\text { Cameron's erosions }\end{array}$ & $\begin{array}{l}\text { Lower gastrointestinal bleeding } \\
\text { Angioectasia }\end{array}$ \\
\hline $\begin{array}{l}\text { Fundic varices } \\
\text { Neoplasms }\end{array}$ \\
\hline $\begin{array}{l}\text { Peptic ulcer } \\
\text { Angioectasia }\end{array}$ \\
\hline Dieulafoy's lesion & \\
\hline Gastric antral vascular ectasia & \\
\hline Causes of middle gastrointestinal bleeding ( less than $\mathbf{4 0}$ years old) \\
\hline Tumors \\
\hline Meckel's diverticulum \\
\hline Dieulafoy's lesion \\
\hline Crohn's disease \\
\hline Causes of middle gastrointestinal bleeding (more than $\mathbf{4 0}$ years old) \\
\hline Angioectasia (Cave ! More than five: establish HHT) \\
\hline NSAID enteropathy \\
\hline Celiac disease \\
\hline Uncommon causes: hemobilia, hemosuccus pancreaticus, aortoenteric \\
fistula
\end{tabular}

disease states. ${ }^{4}$ It frequently contains heterotopic tissue; when it does, gastric mucosa accounts for $50 \%$ like in our case. ${ }^{4}$

Retrospective studies suggest that the onset and frequency of complications decrease during life. ${ }^{5}$

The risk of complications ranges from 4-25 as the following: ulceration, hemorrhage, small bowel obstruction, diverticulitis, perforation. Population-based study covering patient data over 42 years, the lifetime risk of developing a complication that requires surgery was estimated to be $6.4 \% .^{1}$

Haemorrhage is the most common complication, with an incidence of about $20-30 \%$ of all complications. It is more common in children younger than two years and in males. Absolute indications for resection in Meckel's diverticulum are hemorrhage, intestinal obstruction, diverticulitis, and umbilico-ileal fistulas.

Multidetector CT scan with i.v. contrast is in many countries the first choice to localize the acute bleeding. ${ }^{6}$ To detect the 
cause of bleeding we preferred as a therapeutic strategy in our case a mesenteric angiographic and if necessary superselective embolization because the angiographic diagnosis of gastrointestinal bleeding distal to the ligament of Treitz is about $40-50 \%$. This strategy is now under discussion while in patients with acute overt obscure Gl-bleeding immediate capsule endoscopy has higher diagnostic yield and comparable long-term outcomes when compared with angiography. ${ }^{7}$

We did not find any abnormality in the mesenteric angiography. Therefore intraoperative endoscopy was needed as the next step in the diagnostic approach.

Little has been written about the medical treatment of Osler-Weber-Rendu arteriovenous malformations and surgical treatment. A combinatory laparoscopic and intraoperative endoscopic approach was recommended. ${ }^{8}$

HHT is inherited as an autosomal dominant trait with varying penetrance and expression. Mutations in at least five genes can cause $\mathrm{HHT}$, with two major genes on chromosomes 9 (ENG, endoglin) and chromosomes 12 (ACVRL1). These diseases subtypes are designated HHT-1 and $\mathrm{HHT}-2$ respectively. ${ }^{9}$

Hereditary hemorrhagic telangiectasia has a variety of clinical manifestations. The majority of patients with HHT experience only epistaxis, mucocutaneous telengiectasia, and a tendency to develop iron deficiency anemia secondary to blood loss. The various manifestations are epistaxis, gastrointestinal bleeding, mucocutaneous telangiectasia, arteriovenous malformations (pulmonary, cerebral and hepatic). Manifestations of HHT are not generally present at birth, but develop with increasing age. Epistaxis is usually the earliest sign of the disease, often ocuring in the childhood. Pulmonary arteriovenous malformations generally become apparent after puberty; although they may be present during childhood, while mucocutaneous and gastrointestinal telangiectasia develop progressively with the age. By the age of 16 years, approximately $70 \%$ of individuals will have developed some clinical sign of $\mathrm{HHT}$, rising to over $90 \%$ by the age of 40 years. ${ }^{10,11}$ Our case has also history of lower gastrointestinal bleeding for the last 6 years ( from the age of 16 years of age ) which correlates with the published data. ${ }^{11}$

Patients usually have a family history of telangiectasia and recurrent bleeding in other family members. ${ }^{2}$ Bleeding may occur as often as every day or as infrequently as once a month. Blood transfusions are required in $10-30 \%$ of patients. The risk of gastrointestinal tract bleeding increases at approximately 50 years of age. Recurrent painless gastrointestinal bleeding occurs in $10-40 \%$ of patients and generally occurs later in life than epistaxis. Patients may report abdominal pain, which may be due to thrombosis of gastrointestinal arteriovenous malformations. The diagnosis of HHT may be suspected in the patients with the above clinical manifestations, particularly if there is a first degree relative with $\mathrm{HHT}^{2}$
The Consensus criteria- international consensus diagnostic criteria, established in June 1999 by the Scientific Advisory Board of the HHT Foundation International (the Curacao diagnostic criteria) are based on the four following findings: ${ }^{12}$

\section{- Epistaxis - Spontaneous, recurrent nosebleeds}

- Telangiectasias - Multiple characteristic sites (lips, oral cavity, fingers, nose)

- Visceral lesions (eg, gastrointestinal telangiectasia [with or without bleeding], pulmonary arteriovenous malformation [AVM], hepatic AVM, cerebral AVM, spinal AVM)

- Family history - A first-degree relative with HHT

The HHT diagnosis is classified as definite if three criteria are present, possible or suspected if two criteria are present and unlikely if fewer than two criteria are present.

Our case was definitive with three out of the four criteria present and his rectal bleeding was attributed to telangiectasia and erosions to the terminal ileum and the Meckel's diverticulum. Multiplex ligation dependent probe amplification (MLPA) performed without any mutation for ENG, ALK-1, and SMAD-4 genes. It has been seen that $30 \%$ of patients with HHT may not have mutations in the genes for the above given mutations. ${ }^{2}$

Our case describes the rare and difficult situation of the combination of two entities for bleeding and shows that despite the sophisticated methods of investigations, the exploration of a surgeon is still necessary to find the reason for bleeding. Especially in patients with HHT, Meckel's diverticulum should be removed. The management of our case was similar to the above guidelines published in the gastroenterology except the use of capsule endoscopy and Meckel's scan which may not be widely available and is expensive as well. ${ }^{3}$ In a single center prospective study by video capsule endoscopy in 93 patients small-bowel

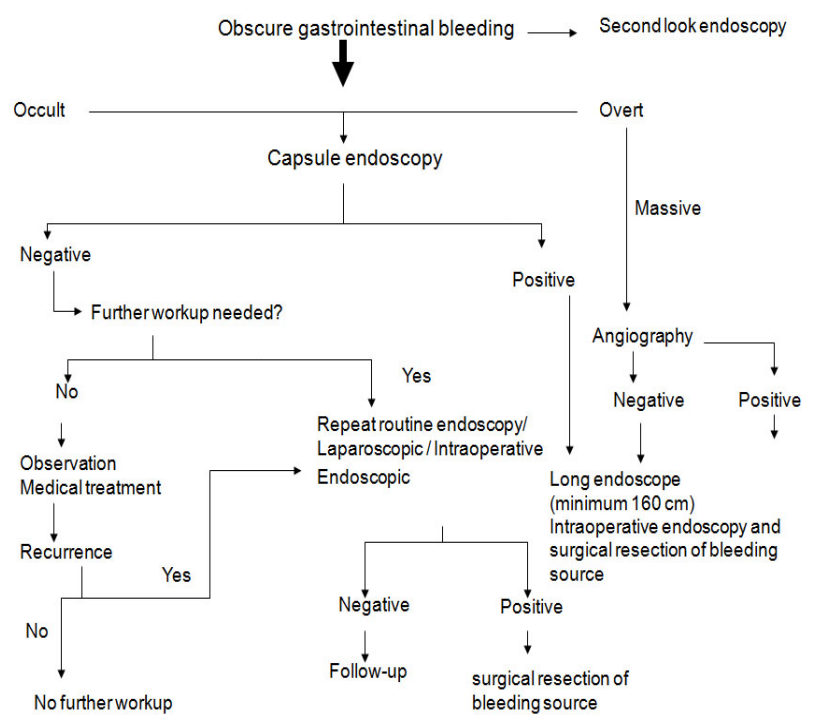

Figure 6. Recommendation for an algorithm in the management of obscure gastrointestinal bleeding for countries with lower medical facilities like Nepal. 
telangiectasias were seen in the majority of patients with HHT and were evenly distributed throughout the small bowel telangiectasias were observed in only a minority of patients who did not have HHT. Actively bleeding smallbowel telangiectasias were located in the proximal and mid-small bowel in patients with $\mathrm{HHT}$, all within reach of an enteroscope. ${ }^{13}$

The management with obscure gastrointestinal bleeding which needs always a close interdisciplinary approach between gastroenterologist, visceral surgeon and

\section{REFERENCES}

1. Cullen JJ, Kelly KA, Moir CR, Hodge DO, Zinsmeister AR, Melton LJ 3rd. Surgical management of Meckel's diverticulum. An epidemiologic population based- study. Ann Surg 1994 Oct; 220(4):564-8.

2. Faughnan ME, Palda VA, garcia-Tsao G, geisthoff UW, Mc Donald J, Proctor DD et al. HHT Foundatin International-Guidelines Working Group.International guidelines for the diagnosis and management of hereditary haemorrhagic telangiectasia.J Med Genet 2011;48:73-87.

3. Raju GS, Gerson L, Das A, Lewis. American Gastroenterological Association (AGA) Institute Technical Review on Obscure Gastrointestinal Bleeding.Gastroenterology 2007; 133(5):1694-6.

4. Dumper J, Mackenzie S, Mitchell P, Sutherland F, Quan ML, Mew D. Complications of Meckel's diverticula in adults.Can J Surg 2006; 49 :353-7.

5. Malik AA, Shams-ul-Bari, Wani KA, Khaja AR. Meckel's diverticulumRevisited. Saudi I Gastroenterol 2010; 6:3-7.

6. Schefel H, Pfammatter T, Wildi S, Bauerfeind P. Acute gastrointestinal bleeding: detection of source of etiology with multidetector row CT. Eur Radiol 2007 June; 17(6): 1555-66.

7. Leung WK, Ho SS, Suen BY, Lai LH, Yu S, Ng EK et al. Capsule endoscopy or angiography in patients with acute overt obscure gastrointestinal bleeding: a prospective randomized study with long-term follow-up. Am J Gastroenterol 2012; 107:1370-6. interventionally experienced radiologist can be followed easily even in countries with lower medical facilities like Nepal. Our proposal is seen in fig 6.

\section{ACKNOWLEDGEMENT}

The authors thank Dr. König (pathologist) for the pathological pictures and Prof. Phillip (gastroenterologist) for the kindly revision of our manuscript.

8. Park J, Ellis B, Juergens C. Laparascopic resection of Osler-WeberRendu lesion.JSLS 2008;12(2):180-2.

9. Govani FS, Shovlin CL. Hereditary haemorrhagic telangiectasia: Hereditary haemorrhagic telangiectasia: a clinical and scientific review. Eur J Hum Genet2009; 17:860-71.

10. Cole SG, Begbie ME, Wallace GM, Shovlin Cl.A new locus for hereditary Haemorrhagic telangiectasia(HHT3) maps to chromosome5. Med gene 2005;42:577-82.

11. Wallace GM, Shovlin CL. A hereditary hemorrhagic telangiectasia family with pulmonary involvement is unlinked to known HHT genes, endoglin and ALK-1. Thorax 2000; 55:6.

12. Shovlin CL, Guttmacher $A E$, Buscarini $E$, Faughnan $M E$, Hyland $\mathrm{RH}$, Westermann CJ, Kjeldsen $A D$, Plauchu H.Diagnostic criteria for hereditary hemorrhagic telangiectasia(Rendu-Osler-Weber syndrome). Am J Med Genet 2000; 9:66-7.

13. Chamberlain SM, Patel J, Carter Balart J, Gossage JR Jr, Sridhar S. Evaluation of patients with hereditary hemorrhagic telangiectasia with video capsule endoscopy: a Single-center prospective study. Endoscopy 2007;39:516-20. 